\section{Discovery of a Near New Star}

Dr. Otto Struve, Yerkes Observatory, reports the discovery of a new star to which the name Wolf 424 has been assigned. It is described as of the twelfth visual magnitude, and its spectrum is of the very late $M$-type. As is well known, it is possible to determine stellar distances to a fair degree of accuracy from their spectral type. The examination of the spectra of stars of known distances shows that the intensities of certain lines in their spectra vary with the true luminosity of the stars. Conversely, by studying lines in the spectra of stars, the real light output can be estimated, and this, combined with the star's apparent brightness, furnishes the necessary data for determining the distance. In the case of the new star, this method has been applied, and the spectroseopic parallax so found shows that it is probably closer to us than $\alpha$ Centauri. It should be pointed out, however, that there is considerable doubt about the true distance, for various reasons. Very great accuracy in determining the intensities of the lines is essential, and in addition, if, as is possible, the star is a very close unresolved binary, this would vitiate the results to some extent. There is no doubt about the star being fairly close to us, for which reason its trigonometrical parallax can be determined in about six months and its distance found by this independent method. Until this has been done, it is advisable to suspend judgment regarding Dr. Struve's conjecture that it may be the nearest star.

\section{Recovery of Comet Gale (I927 vi)}

MR. L. E. Cunningham, at Harvard, recovered this comet in the following position: 1938 May $1^{\mathrm{d}} 5^{\mathrm{h}} 51 \cdot 6^{\mathrm{m}}$ U.T.; R.A. $17^{\mathrm{h}} 23^{\circ} 4^{\mathrm{m}}$; S. Decl. $13^{\circ} 4^{\prime}$; mag. 10. It is described as diffuse without central condensation or nucleus, and there is no report of a tail. Dr. A. C. D. Crommelin has deduced the following elements :

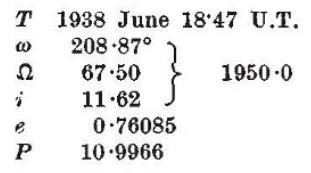

On May 18 the moon passed near the comet. As the object is moving rapidly southward it will be difficult for observers in the northern hemisphere to see it. The following ephemeris may prove useful for those who are favourably placed for observing it:

\begin{tabular}{rrrrrrrr}
\multicolumn{4}{c}{ R.A. $1950^{\circ} 0$} & \multicolumn{3}{c}{ S. Decl. } \\
1938 May $22^{\circ} 0$ & $19^{\text {h }}$ & $4^{\text {m }}$ & $2^{\circ}$ & $41^{\prime}$ & $8 \cdot 7$ \\
$30^{\circ} 0$ & 19 & 55 & 30 & 6 & $8 \cdot 4$ \\
June & $7 \cdot 0$ & 20 & 53 & 34 & 46 & $8 \cdot 2$ \\
$15 \cdot 0$ & 21 & 51 & 37 & 48 & $8 \cdot 2$
\end{tabular}

Dr. R. T. A. Innes has published a long paper on this comet and found a period of 4088.8 days. $\mathrm{He}$ predicted perihelion passage on 1938 August 24 and also a close approach to Jupiter in August 1917 (Mem. Brit. Astro. Assoc., 30, Fifth Report of the Comet Section). As the period is now known with considerable accuracy, it will be possible to examine the closeness of the approach to Jupiter in 1917.

\section{The Evolution of Electrical Power}

DR. A. P. M. Fleming gave a Faraday lecture on "The Evolution of Electrical Power" to the Institu. tion of Electrical Engineers on May 12. Applications of electrical power are to be found in every branch of our modern communal life, and yet few of those who make use of them have any real appreciation of the discoveries in which the modern system of electrical power had its origin, of the part which scientific research has played in making modern developments possible and of the direction in which new scientific discoveries may cause its continuous evolution to proceed. Few men have entered with success, comparable to Faraday's, into such a diversity of fields of investigation. We may well marvel that with only simple self-constructed apparatus available, he was able to formulate laws and lay down principles which have stood the test of time. Since Faraday invented the first electrical generator, numerous types of electrical generators have been developed; but the principle underlying them all is the same.

DR. Fleming directed attention to the continuous increase in the voltages now used, to the change over from direct current to alternating current generation, to the increase in running speeds and to the enormous increase in the power output provided by single machines. These changes are linked with contemporary developments-- to the introduction and improvement of the steam turbine prime mover, and to the rapid growth of central generating stations and their associated transmission and distribution networks. The electromagnetic method is not the only means of converting natural sources of energy into electrical form. The extent to which recent discoveries in the physical sciences, such as those of controlled atomic disintegration, cannot yet be forecast, but it is certain that much that is purely scientific to-day will form the basis of new industrial developments to-morrow. The spirit of Faraday is still at work, but now it works through many brains and with many hands so that who can say where it will lead?

\section{Expedition to Greenland and the Canadian Arctic}

In his Friday evening discourse at the Royal Institution on May 13, Mr. J. M. Wordie described "An Expedition to North-West Greenland and the Canadian Arctic". The objects of the expedition were in part geological, in part archæological, but in the main to investigate cosmic ray intensity near the north geomagnetic pole by means of free floating balloons. The expedition sailed from Leith at the end of June, 1937. The cosmic ray observations were undertaken at various points in West and North. West Greenland, and six flights altogether were made. Two different types of apparatus were in use, one designed by Mr. E. G. Dymond which consisted of a triple-coincidence Geiger counter set with wireless transmission of the counts and the barometric pressure, the other constructed by Dr. H. Carmichael consisting of a miniature ionization chamber with electroscope and a small camera which photographed the latter 